\title{
TNF system activity and plasma RBP4 and apelin-36 levels in obese and normal weight women
}

\author{
Wiesław Folwarczny¹, Piotr Kocełak², Aleksander Owczarek³, Jerzy Chudek2,4, \\ Magdalena Olszanecka-Glinianowicz ${ }^{1}$
}

\author{
${ }^{1}$ Health Promotion and Obesity Management Unit, Department of Pathophysiology, Medical Faculty in Katowice, \\ Medical University of Silesia, Katowice, Poland \\ ${ }^{2}$ Pathophysiology Unit, Department of Pathophysiology, Medical Faculty in Katowice, Medical University of Silesia, \\ Katowice, Poland \\ ${ }^{3}$ Department of Statistics, Department of Instrumental Analysis, School of Pharmacy with the Division of Laboratory \\ Medicine in Sosnowiec, Medical University of Silesia, Katowice, Poland \\ ${ }^{4}$ Department of Internal Medicine and Oncological Chemotherapy, Medical Faculty in Katowice, Medical University \\ of Silesia, Katowice, Poland
}

\begin{abstract}
Objective: Tumour necrosis factor $\alpha$ (TNF- $\alpha$ ), retinol-binding protein 4 (RBP4), and apelin-36 are adipokines with increased circulating levels in obesity, which are involved in the development of insulin resistance. It was shown that TNF- $\alpha$ stimulates synthesis of apelin-36 and inhibits RBP4 expression in adipocytes. The aim of the study was the assessment of relationships between TNF system activity and plasma RBP4 and apelin-36 levels in obese and normal weight women.
\end{abstract}

Material and methods: A total of 116 women (72 obese and 44 normal weight) were enrolled into the study. In addition to the anthropometric measurements and routine biochemical parameters, plasma TNF- $\alpha$, sTNFRs, RBP4, and apelin-36, insulin levels were assessed by ELISA.

Results: In obese group plasma TNF- $\alpha$, sTNFR1, RBP-4, and apelin-36 levels were significantly higher, while sTNFR2 levels were lower than in the normal-weight group (Me 4.4 vs. $2.3 \mathrm{pg} / \mathrm{mL}, p<0.05 ; 1908 \mathrm{vs.} 1285 \mathrm{pg} / \mathrm{mL}$, $p<0.001 ; 27.6$ vs. $14.7 \mathrm{ng} / \mathrm{mL}, p<0.001 ; 1.6$ vs. $1.2 \mathrm{ng} / \mathrm{mL}, p<0.05$, and 2361 vs. $2574 \mathrm{pg} / \mathrm{mL}, p<0.05$, respectively). Multivariate regression analysis revealed that plasma RBP4 levels were proportional to age $(\beta=0.01)$, and plasma TNF- $\alpha(\beta=0.26)$ and sTNFR1 $(\beta=0.39)$ levels, and inversely proportional to sTNFR2 levels $(\beta=-0.55)$ independently of body mass index (BMI) and waist circumference, while apelin-36 was proportional to BMI $(\beta=0.01)$ and insulin levels $(\beta=0.19)$ and inversely proportional to age $(\beta=-0.01)$, independently of waist circumference and TNF system activity.

Conclusions: Plasma RBP4, but not apelin-36 level, is associated with TNF system activity.

Key words: apelin, RBP4, TNF system, nutritional status.

\section{Introduction}

Excessive visceral fat accumulation is associated with macrophage infiltration of adipose tissue, activation of lipolysis, hormonal function disturbances, and insulin resistance development [1]. It has been shown that both macrophages and adipocytes are a source of tumour necrosis factor $\alpha$ (TNF- $\alpha$ ), and its production and secretion increase proportionally to adipocytes volumes [2]. It is well known that circulating TNF- $\alpha$ levels are increased in obese subjects $[3,4]$ and decreased after weight loss $[5,6]$. Additionally, our previously published results revealed that circulating TNF- $\alpha$ levels increase in the early stage of visceral obesity development [7] sequent weight gain cause a slight influence of systemic microinflammation and seems not to lose the benefit achieved with weight loss [8]. However, it has been suggested that, in terms of TNF- $\alpha$, we should rather talk about the TNF system in- 
cluding the membrane (TNFI and TNFRII) and soluble (sTNFR1 and sTNFR2) receptors [9-11]. TNFRI activation stimulates apoptosis, cell proliferation and growth, and inflammation, while TNFRII activation stimulates growth of thymocytes, cytotoxicity of T lymphocytes, production of other proinflammatory cytokines, insulin resistance development, and regulated binding of TNF- $\alpha$ to sTNFR1 [12]. Soluble TNF receptors are generated by proteolytic splitting of the extracellular part of the membrane receptors, and the process is stimulated by TNF- $\alpha$ [9]. sTNFR1 probably plays a key role in insulin resistance development [13]. As was mentioned above, inflammation in adipose tissue and increased TNF- $\alpha$ secretion is associated with adipokines release disturbances. The results of experimental studies revealed that TNF- $\alpha$ inhibits expression of mRNA retinol-binding protein 4 (RBP4) in adipocytes [14,15], while Erikstrup et al. [16] found that TNF- $\alpha$ may play a role in ectopic fat accumulation in muscles stimulated by RBP4. Additionally, it has been shown that in subjects diagnosed with type 2 diabetes and coronary artery disease, circulating RBP4 levels were associated with TNF-a levels, but not with insulin resistance [17]. Increased circulating RBP4 levels were described in obese subjects [18-21]. It is interesting that both TNF- $\alpha$ and RBP4 participate in insulin resistance development by similar mechanisms, including suppression of tyro-

Table 1. Study groups' characteristics

\begin{tabular}{|l|c|c|c|}
\hline Parameter & $\begin{array}{c}\text { Obese } \\
(n=72)\end{array}$ & $\begin{array}{c}\text { Normal } \\
\text { weight } \\
(n=44)\end{array}$ & \\
\hline Age (years) & $38.1 \pm 11.6$ & $30.3 \pm 11.0$ & $<0.001$ \\
\hline Body mass $(\mathrm{kg})$ & $95.3 \pm 16.8$ & $60.4 \pm 6.9$ & $<0.001$ \\
\hline BMI $\left(\mathrm{kg} / \mathrm{m}^{2}\right)$ & $35.4 \pm 6.0$ & $22.6 \pm 2.2$ & $<0.001$ \\
\hline Body fat $(\mathrm{kg})$ & $48.0 \pm 13.4$ & $19.2 \pm 4.6$ & $<0.001$ \\
\hline Body fat $(\%)$ & $47.1 \pm 7.1$ & $31.4 \pm 5.0$ & $<0.001$ \\
\hline Waist circumference $(\mathrm{cm})$ & $106.4 \pm 14.4$ & $73.0 \pm 9.1$ & $<0.001$ \\
\hline Total cholesterol $(\mathrm{mg} / \mathrm{dL})$ & $197.1 \pm 36.9$ & $184.4 \pm 43.0$ & NS \\
\hline LDL-cholesterol $(\mathrm{mg} / \mathrm{dL})$ & $120.5 \pm 35.5$ & $106.7 \pm 41.1$ & NS \\
\hline HDL-cholesterol $(\mathrm{mg} / \mathrm{dL})$ & $54.5 \pm 12.5$ & $60.3 \pm 15.0$ & $<0.05$ \\
\hline Triglycerides $(\mathrm{mg} / \mathrm{dL})$ & $101.0 / 59.0$ & $65.0 / 35.0$ & $<0.001$ \\
\hline Glucose $(\mathrm{mmol} / \mathrm{L})$ & $5.1 \pm 0.6$ & $4.8 \pm 0.6$ & $<0.01$ \\
\hline Insulin $(\mu \mathrm{IU} / \mathrm{mL})$ & $8.5 / 7.3$ & $6.7 / 3.8$ & $<0.01$ \\
\hline HOMA-IR & $1.7 / 1.8$ & $1.5 / 1.0$ & $<0.01$ \\
\hline TNF- $\alpha(\mathrm{pg} / \mathrm{mL})$ & $4.4 / 4.1$ & $2.3 / 4.1$ & $<0.05$ \\
\hline sTNFR1 $(\mathrm{pg} / \mathrm{mL})$ & $1909 / 1163$ & $1285 / 472$ & $<0.001$ \\
\hline sTNFR2 $(\mathrm{pg} / \mathrm{mL})$ & $2361 / 637$ & $2574 / 1259$ & $<0.05$ \\
\hline RBP4 $(\mathrm{ng} / \mathrm{mL})$ & $27.6 / 20.4$ & $14.7 / 14.2$ & $<0.001$ \\
\hline Apelin-36 $(\mathrm{ng} / \mathrm{mL})$ & $1.6 / 1.1$ & $1.2 / 0.9$ & $<0.05$ \\
\hline
\end{tabular}

sine autophosphorylation in type 1 substrate of insulin receptor, inhibition of inositol phosphorylate kinase 3 signalling, and GLUT4 expression in adipocytes, as well as stimulation of gluconeogenesis pathways enzymes in hepatocytes $[22,23]$. Apelin is another adipokine with increased circulating levels in obesity. Its synthesis is stimulated by insulin or glucose levels [24]. In turn, apelin inhibits insulin release [25]. It has also been shown that growth hormone and TNF- $\alpha$ stimulates apelin mRNA expression in adipocytes $[26,27]$. However, there is a lack of studies assessing associations between TNF system activity and circulating RBP4 and apelin levels.

Therefore, the aim of this study was the assessment of the relationships between TNF system activity and plasma RBP4 and apelin-36 levels in obese and normalweight women.

\section{Material and methods}

The cross-sectional study involved 116 women ( 44 normal weight and 72 obese) with stable body mass during the last three-month period. The obese women were not diagnosed with any complications of obesity or other chronic diseases. The normal-weight women were apparently healthy. The exclusion criteria included: evidence of present or recent (last three months) infectious disease, cigarette smoking, and any medication.

The study was conducted after obtaining of informed consent from each participant. The study protocol was approved by the Bioethical Committee of the Medical University of Silesia.

Normal weight was defined according to World Health Organisation (WHO) criteria [28] as body mass index (BMI) from 18.5 to $24.9 \mathrm{~kg} / \mathrm{m}^{2}$ and obesity as $\geq 30.0 \mathrm{~kg} / \mathrm{m}^{2}$. The characteristics of the analysed groups are listened in Table 1.

Anthropometric measurements (body mass, height, and waist circumference) were performed, and the BMI was calculated according to the standard formula. Body composition was assessed by the bioimpedance method using a Bodystat 1500 (Douglas, Isle of Man).

Samples of venous blood $(15 \mathrm{~mL})$ were withdrawn between 8.00 and 9.00 a.m., after an overnight fast $(16 \mathrm{~h})$. The blood samples were collected according to recommendations of the kits' manufacturers. Serum and plasma samples were frozen and stored at $-70^{\circ} \mathrm{C}$.

\section{Laboratory procedures}

Plasma glucose and lipids were estimated by colorimetric methods using commercially available test kits (Roche, Switzerland). Serum insulin concentration was determined by enzyme-linked immunosorbent assay (ELISA) (DRG Instruments GmbH, Marburg, Germany) with a lower limit of sensitivity of $1.76 \mathrm{uU} / \mathrm{mL}$ and in- 
tra- and inter-assay coefficients of variations of $2.2 \%$ and $4.4 \%$, respectively. HOMA-IR index was calculated with the standard formula: HOMA-IR = fasting concentration of insulin $(\mathrm{uU} / \mathrm{mL}) \times$ fasting concentration of glucose (mmol/L) / 22.5 .

ELISA method was also used for measurements of plasma TNF- $\alpha$ and sTNFRs (R\&D System, Minnesota, MN, USA), RBP4, and apelin-36 (Phoenix Pharmaceuticals, Burlingame, USA) levels with the lower limit of sensitivity of $0.18 \mathrm{pg} / \mathrm{mL}, 0.77 \mathrm{pg} / \mathrm{mL}, 0.6 \mathrm{pg} / \mathrm{mL}, 2.17 \mathrm{ng} / \mathrm{mL}$, and $0.11 \mathrm{ng} / \mathrm{mL}$, respectively, and intra- and inter-assay coefficients of variations were $14.4 \%$ and $18.7 \%$ for TNF- $\alpha, 3.6 \%$ and $2.6 \%$ for sTNFR1, 3.7\% and $3.5 \%$ for sTNFR2, $5.0 \%$ and $<14.0 \%$ for RBP4 and $5.0-10.0 \%$ and $<15.0 \%$ for apelin-36.

\section{Statistical analysis}

Statistical analysis was performed using STATISTICA 9.0 PL (StatSoft, Cracow, Poland) software and the $\mathrm{R}$ software environment. There were no missing data in the database. The results are presented as mean values \pm standard deviation and as median and interquartile range for the data deviating from the normal distribution percentages for the data in nominal and ordinal scale. Distribution of variables was evaluated by the D'Agostino-Pearson test. Homogeneity of variances was assessed by the Levene test. Quantitative variables were compared with two-way multivariate analysis of variance with Duncan test post-hoc. The assessment of associations between variables was done with the multivariate linear regression and the backward stepwise procedure. Outliers were identified based on Cook's distance values. The Cook-Weisberg test was used to test the residuals for heteroskedasticity. Model calculation was performed, including evaluation of multicollinearity, which was assessed with the variance inflation factor (VIF). The VIF should not exceed more than 5 . Goodness of fit of the obtained model was assessed with the $\mathrm{F}$ test and determination coefficient $R^{2}$. All the results were considered as statistically significant with a $p$ value of $<0.05$.

\section{Results}

The serum concentrations of cholesterol and low-density lipoprotein (LDL) cholesterol were similar in the study and control groups. Serum triglyceride levels were significantly higher and high-density lipoprotein (HDL) cholesterol levels lower in obese than in normal-weight women (Table 1).

Serum glucose and insulin levels as well as HOMA-IR values were significantly higher in the study group than in the control group (Table 1).

Plasma TNF- $\alpha$, sTNFR1, RBP4, and apeliny-36 levels were significantly higher and sTNFR2 lower in obese women than in normal-weight women (Table 1). According to the results of ROC analysis, obese women were characterised by plasma TNF- $\alpha$ levels $\geq 2.60 \mathrm{pg} / \mathrm{mL}$ (with $70.5 \%$ sensitivity and $59.5 \%$ specificity), sTNFR1 levels $\geq 1335 \mathrm{pg} / \mathrm{mL}$ (with $70.3 \%$ sensitivity and $54.8 \%$ specificity), sTNFR2 levels $\leq 2447 \mathrm{pg} / \mathrm{mL}$ (with $61.9 \%$ sensitivity and $58.1 \%$ specificity), RBP4 levels $\geq 18.7 \mathrm{ng} / \mathrm{mL}$ (with $68.9 \%$ sensitivity and $66.7 \%$ specificity), and apelin-36 levels $\geq 1.41 \mathrm{ng} / \mathrm{mL}$ (with $63.5 \%$ sensitivity and $61.9 \%$ specificity).

\section{Correlation between anthropometric parameters and study adipokines}

Plasma TNF- $\alpha$ levels correlated positively with body mass, BMI, and waist circumference $(R=0.19, p<0.05$; $R=0.22, p<0.05$ and $R=0.29, p<0.01$, respectively). There were also positive correlations between sTNFR1 and body mass, BMI, and waist circumference $(R=0.25$, $p<0.01 ; R=0.27, p<0.01$ and $R=0.32, p<0.001$, respectively). Plasma RBP4 levels were also proportional to body mass, BMI, body fat mass, and waist circumference $(R=0.35, p<0.001 ; R=0.36, p<0.001 ; R=0.24$, $p<0.01$ and $R=0.47, p<0.001$, respectively). We also observed positive associations between apelin-36 levels and body mass, and body fat mass $(R=0.19, p<0.05$ and $R=0.30, p<0.01$, respectively). There were negative correlations between sTNFR2 levels and body mass, BMI, body fat mass, and waist circumference $(R=-0.26, p<0.01$; $R=-0.23, p<0.05 ; R=-0.21, p<0.05$ and $R=-0.29$, $p<0.01$, respectively).

Additionally, there was a positive correlation between age and TNF- $\alpha$, sTNFR1, and RBP4 levels $(R=0.63$, $p<0.001 ; R=0.37, p<0.001$ and $R=0.60, p<0.001$, respectively) and negative with sTNFR2 and apelin-36 levels $(R=-0.30, p<0.01$ and $R=-0.27, p<0.01$, respectively) in all study groups.

\section{Correlation between lipid, glucose, and insulin concentrations as well as HOMA-IR values and study adipokines}

Serum cholesterol and LDL cholesterol concentrations were proportional to TNF- $\alpha$ and RBP4 levels $(R=0.43, p<0.001 ; R=0.50, p<0.001$ and $R=0.40$, $p<0.001 ; R=0.45, p<0.001$, respectively) and inversely proportional to $\operatorname{sTNFR} 2(R=-0.37, p<0.001$ and $R=0.31, p<0.001$, respectively). There were no associations between HDL cholesterol and the study adipokine levels.

There was a positive correlation between serum triglycerides concentrations and TNF- $\alpha$, sTNFR1, and RBP4 levels $(R=0.36, p<0.001 ; R=0.30, p<0.01$ and $R=0.39, p<0.001$, respectively).

Serum glucose concentrations were proportional to TNF- $\alpha$, sTNFR1, and RBP4 levels $(R=0.35, p<0.001$; 
$R=0.26, p<0.01$ and $R=0.48, p<0.001$, respectively) and inversely proportional to $\operatorname{sTNFR} 2(R=-0.21$, $p<0.05)$, while insulin levels were associated with apelin-36 levels only $(R=0.19, p<0.05)$. There was no correlation between HOMA-IR values and the studied adipokines.

\section{Correlation between the studied adipokines}

Plasma RBP4 levels were proportional to TNF- $\alpha$ and sTNFR1 levels $(R=0.61, p<0.001 ; R=0.46, p<0.001$, respectively) and inversely proportional to sTNFR2 $(R=-0.41, p<0.001)$. Plasma apelin-36 levels were negatively associated with TNF- $\alpha$ levels only $(R=-0.34$, $p<0.001)$.

\section{Multiple regression analyses}

The multivariate regression analysis revealed that plasma RBP4 level was proportional to age $(\beta=0.01$, $p<0.001)$, plasma TNF- $\alpha(\beta=0.26, p<0.001)$, and sTNFR1 $(\beta=0.39, p<0.001)$ levels and inversely proportional to sTNFR2 level $(\beta=-0.55, p<0.001)$, regardless of the BMI and waist circumference, while apelin-36 was proportional to BMI $(\beta=0.01, p<0.05)$ and insulin level $(\beta=0.19, p<0.05)$ and inversely proportional to age $(\beta=-0.01, p<0.001)$, regardless of the waist circumference and TNF system activity.

\section{Discussion}

In accordance with the results of previously published studies [3,4,18,19,29-35], plasma TNF- $\alpha$, sTNFR1, RBP4, and apelin-36 levels are significantly higher in obese than in normal weight women. However, contrary to earlier studies, circulating sTNFR2 levels were lower in obese than in normal-weight women [13,36,37]. Moreover, we observed that circulating TNF- $\alpha$, sTNFR1, RBP4, and apelin-36 levels were proportional to nutritional status, but visceral obesity was associated with higher TNF- $\alpha$, sTNFR1, and RBP4 but not with apelin-36 levels, while the sTNFR2 levels were inversely proportional to nutritional status and visceral obesity. We suggest that the decrease of circulating sTNFR2 in obese subjects is a contraregulatory mechanism for the increased TNF- $\alpha$ and sTNFR1 levels. This hypothesis is confirmed by our previously published results which showed that sTNFR2 levels increased after weight loss [8]. In contrast to this data are our results showing increases of both sTNFR1 and sTNFR2 levels during the development of the early stage of visceral obesity in the five-year follow-up [7]. Further studies are necessary to verify our hypothesis because of the poor understanding of the role of sTNFRs in the development of obesity complications.
This study is the first to assess the cut-off points of study adipokines characteristic for obesity. However, further studies in large homogenous group are necessary to prove this observation. Moreover, the gender, age, and race as well as visceral fat depot-related variability for these cut-off points may preclude their generalisation. Their establishment seems to be valid in terms of potential practical use of adipokine evaluation.

It has been shown that both TNF- $\alpha$ and RBP4 participated in insulin resistance development $[13,22,23]$. However, we did not observe associations between these adipokine circulating levels and insulin resistance assessed on the basis HOMA-IR values, while, contrary to some studies [2,38], serum glucose concentrations were proportional to TNF- $\alpha$, sTNFR1 but in accordance with other studies [18,39-41] regarding RBP4 levels. Moreover, according to previously published results $[24,42]$, our study showed that the circulating insulin concentration is proportional to apelin-36 level.

Additionally, we observed an association between circulating TNF- $\alpha$ and RBP4 but not apelin-36 levels with serum total cholesterol, LDL cholesterol, and triglycerides concentrations. These results are in accordance with experimental and clinical studies [43-48]. Moreover, serum cholesterol and LDL cholesterol concentrations were inversely proportional to sTNFR2. Our results indicate that a decrease of circulating sTNFR2 levels in obesity is the contraregulatory mechanism partially preventing the negative metabolic action of TNF- $\alpha$ and sTNFR1. However, further studies, especially experimental ones, are necessary to clarify this hypothesis.

The novelty of our study is that plasma RBP4 levels are proportional to TNF- $\alpha$ and sTNFR1 and inversely proportional to sTNFR2, independently of nutritional status. This observation was confirmed by the results of multiple regression analysis. An additional factor explaining RBP4 level variability was age, regardless of the BMI and waist circumference. However, apelin-36 levels were proportional to BMI and insulin levels and inversely proportional to age, regardless of the waist circumference and TNF system activity. Our findings are in accordance with results that showed that RBP4 mRNA expression in adipocytes is proportional to circulating TNF-a levels [15], and a clinical study in subjects diagnosed with type 2 diabetes [17]. These results are in contrast to experimental studies that showed that TNF- $\alpha$ inhibits RBP4 mRNA expression in adipocytes and hepatocytes $[14,16,49]$. Therefore, it seems that TNF system activity changes are the factor participating in glucose and lipid metabolism disturbances directly and indirectly by stimulating the RBP4 release, while the impact on apelin-36 affects both nutritional status and insulin levels but not TNF system activity. These results are in part contrary to previously published studies, which showed that plasma apelin levels are proportional 
to circulating TNF- $\alpha$ in subjects diagnosed with type 2 diabetes [42], and experimental studies that revealed that mRNA apelin in adipocytes and its circulating levels increases after TNF- $\alpha$ infusion in mice [50]. However, in accordance with our results in 3T3-L1 adipocyte cultures, TNF- $\alpha$ did not influence the apelin mRNA expression [26]. Additionally, our study showed that both nutritional status and insulin levels are factors influencing circulating apelin levels. Thus, we suggest that increased apelin levels are the effect of a contraregulatory mechanism preventing insulin resistance development. This hypothesis is confirmed by the experimental study showing that apelin stimulates insulin signalling and increased glucose uptake [51]. Moreover, the lack of TNF system activity on circulating apelin-36 levels suggests that this adipokine release is independent of adipose tissue inflammation and the mechanism is secondary to impaired glucose up-take mediated by TNF system activity and RBP 4 changes. This hypothesis is confirmed by the results of a study showing that weight reduction and insulin sensitivity improvement is associated with decreased apelin levels [33].

The limitation of our study is the size of study subgroups. Moreover, the distribution of body fat and its visceral deposits were not directly assessed using DEXA or a CT scanner. Additionally, only apelin-36 isoform was measured.

\section{Conclusions}

Plasma RBP4 but not apelin-36 levels are associated with TNF system activity.

\section{Disclosure}

Research relating to this manuscript was funded by a Medical University of Silesia grant.

The authors report no conflict of interest.

\section{References}

1. Olszanecka-Glinianowicz M, Zahorska-Markiewicz B. Obesity as inflammatory disease. Postepy Hig Med Dosw (Online) 2008; 62: 249-257.

2. Winkler G, Kiss S, Keszthelyi L, et al. Expression of tumor necrosis factor (TNF)- $\alpha$ protein in the subcutaneous and visceral adipose tissue in correlation with adipocyte cell volume, serum TNF- $\alpha$, soluble serum TNF-receptor-2 concentrations and C-peptide level. Europ J Endocrinol 2003; 149: 129-135.

3. Zahorska-Markiewicz B, Janowska J, Olszanecka-Glinianowicz M, Żurakowski A. Serum concentrations of TNF-alpha and soluble TNF-alpha receptors in obesity. Internat J Obes Relat Metab Di 2000; 24: 1392-1395.

4. Olszanecka-Glinianowicz M, Zahorska-Markiewicz B, Janowska J, Żurakowski A. Serum concentrations of nitric oxide, tumor necrosis factor (TNF)-alpha and TNF soluble receptors in women with overweight and obesity. Metabolism 2004; 53: 1268-1273.

5. Olszanecka-Glinianowicz M, Zahorska-Markiewicz B, Janowska J. The effect of weight loss on serum concentrations of nitric ox- ide, TNF-alpha and soluble TNF-alpha receptors. Endokrynol Pol 2006; 57: 487-493.

6. Zahorska-Markiewicz B, Olszanecka-Glinianowicz M, Janowska J, Kocełak P. The effect of weight loss on serum concentrations of FAS and tumor necrosis factor alpha in obese women. Endokrynol Pol 2008; 59: 18-22.

7. Olszanecka-Glinianowicz M, Chudek J, Kocełak P, et al. Body fat changes and activity of tumor necrosis factor $\alpha$ system-a 5 -year follow-up study. Metabolism 2011; 60: 531-536.

8. Olszanecka-Glinianowicz M, Chudek J, Szromek A, ZahorskaMarkiewicz B. Changes of systemic microinflammation after weight loss and regain - a five-year follow up study. Endokrynol Pol 2012; 63: 432-438.

9. Diez-Ruiz A, Tilz GP, Zangerle R, Baier-Bitterlich G, Wachter H. Soluble receptors for tumour necrosis factor in clinical labolatory diagnosis. Eur J Hematol 1995; 54: 1-8.

10. Old LJ. Tumor necrosis factor (TNF). Science 1985; 230: 630-632.

11. Peraldi P, Spiegelman B. TNF-alpha and insulin resistance: summary and future prospects. Mol Cell Biochem 1998; 182: 169-175.

12. Schreyer SA, Streamson CC, LeBoeuf RC. Obesity and diabetes in TNF-a receptor - deficient mice. J Clin Invest 1998; 102: 402-411.

13. Hauner $\mathrm{H}$, Bender $\mathrm{M}$, Haastert B, Hube F. Plasma concentrations of soluble TNF- $\alpha$ receptors in obese subjects. Intern J Obes Relat Metab Disord 1998; 22: 1239-1243.

14. Broch M, Ramírez R, Auguet MT, et al. Macrophages are novel sites of expression and regulation of retinol binding protein-4 (RBP4). Physiol Res 2010; 59: 299-303.

15. Terra X, Auguet T, Broch $M$, et al. Retinol binding protein-4 circulating levels were higher in nonalcoholic fatty liver disease vs. histologically normal liver from morbidly obese women. Obesity (Silver Spring) 2013; 21: 170-177.

16. Erikstrup C, Mortensen OH, Nielsen AR, et al. RBP-to-retinol ratio, but not total RBP, is elevated in patients with type 2 diabetes. Diabetes Obes Metab 2009; 11: 204-212.

17. Al-Daghri NM, Al-Attas OS, Alokail M, et al. Retinol binding protein-4 is associated with TNF-alpha and not insulin resistance in subjects with type 2 diabetes mellitus and coronary heart disease. Dis Markers 2009; 26: 135-140.

18. Graham TE, Yang Q, Blüher M, et al. Retinol-binding protein 4 and insulin resistance in lean, obese and diabetic subjects. New Engl J Med 2006; 354: 2552-2563.

19. Broch $M$, Auguet MT, Ramírez R, et al. Parallel down-regulation of retinol binding protein-4 (RBP4) and adiponectin expression in subcutaneous adipose tissue of non - morbidly obese subjects. Europ J Endocrinol 2009; 161: 87-94.

20. Klöting N, Graham TE, Berndt J, et al. Serum retinol-binding protein is more highly expressed in visceral than in subcutaneous adipose tissue and is a marker of intra-abdominal fat mass. Cell Metab 2007; 6: 79-87.

21. Hermsdorff HH, Zulet MA, Puchau B, Martínez JA. Central adiposity rather than total adiposity measurements are specifically involved in the inflammatory status from healthy young adults. Inflammation 2011; 34: 161-170.

22. Yang Q, Graham TE, Mody N, et al. Serum retinol binding protein 4 contributes to insulin resistance in obesity and type 2 diabetes. Nature 2005; 436: 356-362.

23. Tamori Y, Sakaue H, Kasuga M. RBP4, an unexpected adipokine. Nature Med 2006; 12: 30-31.

24. Boucher J, Masri B, Daviaud D, et al. Apelin, a newly identified adipokine up-regulated by insulin and obesity. Endocrinology 2005; 146: 1764-1771.

25. Guo L, Li Q, Wang W, et al. Apelin inhibits insulin secretion in pancreatic beta-cells by activation of Pl3-kinase-phosphodiesterase 3B. Endoc Res 2009; 34: 142-154. 
26. Daviaud D, Boucher J, Gesta S, et al. TNF-alpha up-regulates apelin expression in human and mouse adipose tissue. FASEB J 2006; 20: 1528-1530.

27. Kralisch S, Lossner U, Bluher M, et al. Growth hormone induces apelin mRNA expression and secretion in mouse 3T3-L1 adipocytes. Regul Pept 2007; 139: 84-89.

28. Olszanecka-Glinianowicz M, Waluszek-Kończakowska I, Zahorska-Markiewicz B, Janowska J. Serum tumor necrosis factor alpha and its soluble receptors in obese women diagnosed with type 2 diabetes and without concomitant diseases. Endokrynol Pol 2005; 56: 174-178.

29. Kern PA, Saghizadeh M, Ong JM, et al. The expression of tumor necrosis factor in human adipose tissue. Regulation by obesity, weight loss, and relationship to lipoprotein lipase. J Clin Invest 1995; 95: 2111-2119.

30. Park HS, Park JY, Yu R. Relationship of obesity and visceral adiposity with serum concentrations of CRP, TNF-alpha and IL-6. Diabetes Res Clin Pract 2005; 69: 29-35.

31. Tsigos C, Kyrou I, Chala E, et al. Circulating tumor necrosis factor alpha concentrations are higher in abdominal versus peripheral obesity. Metabolism 1999; 48: 1332-1335.

32. Zahorska-Markiewicz B, Mizia-Stec K, Olszanecka-Glinianowicz $M$, Janowska J. Effect of weight reduction on serum ghrelin and TNF alpha concentrations in obese women. Europ J Intern Med 2004; 15: 172-175.

33. Castan-Laurell I, Vitkova M, Daviaud D, et al. Effect of hypocaloric diet-induced weight loss in obese women on plasma apelin and adipose tissue expression of apelin and APJ. Europ J Endocrinol 2008; 158: 905-910.

34. Li L, Yang G, Li Q, et al. Changes and relations of circulating visfatin, apelin, and resistin levels in normal, impaired glucose tolerance, and type 2 diabetic subjects. Exper Clin Endocrinol Diabetes 2006; 114: 544-548.

35. Adamska A, Nikołajuk A, Karczewska-Kupczewska M, et al. Relationships between serum adiponectin and soluble TNF- $\alpha$ receptors and glucose and lipid oxidation in lean and obese subjects. Acta Diabetol 2012; 49: 17-24.

36. Gupta A, Ten S, Anhalt H. Serum levels of soluble tumor necrosis factor-alpha receptor 2 are linked to insulin resistance and glucose intolerance in children. J Ped Endocrinol Metab 2005; 18: 75-82.

37. Bertin E, Nguyen P, Guenounou M, et al. Plasma levels of tumor necrosis factor (TNF-alpha) are essentially dependent on visceral fat amount in type 2 diabetic patients. Diabetes Metab 2000; 26: 178-182.

38. Gao S, Li M, Wang Z, et al. Serum levels of retinol-binding protein-4 and its association with metabolic syndrome in first-degree relatives of type 2 diabetes mellitus. Zhonghua Yi Xue Za Zhi 2009; 89: 2129-2133.

39. Mostafaie N, Sebesta C, Zehetmayer S, et al. Circulating retinol-binding protein 4 and metabolic syndrome in the elderly. Wien Med Wochenschr 2011; 161: 505-510.

40. Li L, Wang C, Bao Y, et al. Serum retinol-binding protein 4 is associated with insulin secretion in Chinese people with normal glucose tolerance. J Diabetes 2009; 1: 125-130.

41. Li L, Yang G, Li $Q$, et al. Changes and relations of circulating visfatin, apelin, and resistin levels in normal, impaired glucose tolerance, and type 2 diabetic subjects. Exper Clin Endocrinol Diabetes 2006; 114: 544-548.

42. Krauss RM, Grunfeld C, Doerrler WT, Feingold KR. Tumor necrosis factor acutely increases plasma levels of very low density lipoproteins of normal size and composition. Endocrinology 1990; 127: 1016-1021.

43. Ito H, Ohshima A, Tsuzuki M, et al. Association of serum tumour necrosis factor-alpha with serum low-density lipoprotein-cho- lesterol and blood pressure in apparently healthy Japanese women. Clin Exper Pharmacol Physiol 2001; 28: 188-192.

44. Moon YS, Kim DH, Song DK. Serum tumor necrosis factor-alpha levels and components of the metabolic syndrome in obese adolescents. Metabolism 2004; 53: 863-867.

45. Park H, Green MH, Shaffer ML. Association between serum retinol-binding protein 4 concentrations and clinical indices in subjects with type 2 diabetes: a meta-analysis. J Hum Nutr Diet 2012; 25: 300-310.

46. Rhie, YJ, Choi BM, Eun SH, et al. Association of serum retinol binding protein 4 with adiposity and pubertal development in Korean children and adolescents. J Korean Med Sci 2011; 26: 797-802.

47. Meisinger C, Rückert, IM, Rathmann, W, et al. Retinol-binding protein 4 is associated with prediabetes in adults from the general population: the Cooperative Health Research in the Region of Augsburg (KORA) F4 Study. Diabetes Care 2011; 34: 1648-1650.

48. Sell H, Eckel J. Regulation of retinol binding protein 4 production in primary human adipocytes by adiponectin, troglitazone and TNF-alpha. Diabetologia 2007; 50: 2221-2223.

49. Heinonen, MV, Laaksonen, DE, Karhu T, et al. Effect of diet-induced weight loss on plasma apelin and cytokine levels in individuals with the metabolic syndrome. Nutr Metab Cardiovascul Dis 2009; 19: 626-633.

50. Yue $\mathrm{P}$, Jin $\mathrm{H}$, Aillaud $\mathrm{M}$, et al. Apelin is necessary for the maintenance of insulin sensitivity. Am J Physiol Endocrinol Metab 2010; 298: E59-67.

51. Krist J, Wieder K, Klöting N, et al. Effects of weight loss and exercise on apelin serum concentrations and adipose tissue expression in human obesity. Obes Facts 2013; 6: 57-69. 